\title{
An Overview of Land Degradation and Sustainable Land Management in the Near East and North Africa
}

\author{
F. M. Ziadat ${ }^{1}$, P. Zdruli ${ }^{2}$, S. Christiansen ${ }^{3}$, L. Caon ${ }^{1}$, M. Abdel Monem ${ }^{4} \&$ T. Fetsi ${ }^{1}$ \\ ${ }^{1}$ Food and Agriculture Organization (FAO) of the United Nations, Land and Water Division, Viale delle Terme \\ di Caracalla, 00153 Rome, Italy \\ ${ }^{2}$ International Centre for Advanced Mediterranean Agronomic Studies (CIHEAM) - Mediterranean Agronomic \\ Institute of Bari, Land and Water Resources Management Department, Via Ceglie 9, 70010 Valenzano (BA), \\ Italy. \\ ${ }^{3}$ Independent Consultant, 61526 West Ridge Ave, Bend, OR 97702, USA \\ ${ }^{4}$ FAO Regional Office for Near East and North Africa, 11 Al-Eslah Al-Zerai Street, Dokki, Cairo, Egypt \\ Correspondence: F. M. Ziadat, Food and Agriculture Organization (FAO) of the United Nations, Land and Water \\ Division, Viale delle Terme di Caracalla, 00153 Rome, Italy. E-mail: feras.ziadat@fao.org
}

Received: September 4, 2021 Accepted: November 4, 2021 Online Published: December 18, 2021

doi:10.5539/sar.v11n1p11 URL: https://doi.org/10.5539/sar.v11n1p11

\begin{abstract}
Land degradation and desertification (LDD) and climate change are having increased effects in the Near East and North Africa (NENA) impacting the livelihoods of about 410 million people. Agriculture is a vital sector, contributing on average 14\% to the Gross Domestic Product (GDP) (excluding oil producing countries) and providing jobs and incomes for $38 \%$ of the region's economically active population. Nevertheless, most NENA countries import at least $50 \%$ of the calories they consume. Furthermore, it is estimated that the total area that is desertified or is vulnerable to desertification cover 9.84 million $\mathrm{km}^{2}$ or about $86.7 \%$ of the total NENA region. Soil erosion by water, wind, and sand and dust storms (SDS) cause losses of about USD 13 billion of GDP each year. To confront these hardships, the region must endorse proper land use planning, prioritization of target areas for restoration and adoption of sustainable land and water management (SLWM) to reverse the situation. This paper analyses the inter-linkages between LDD, resource base management and food security under different scenarios and offers mitigation and remediation options. These include knowledge management and sharing; establishment of a regional platform to facilitate dialogue; public and private investment opportunities; provision of tools to scale-out sustainable land and water management options; and creation of a conducive enabling environment supported by policies and strategies. The paper provides policy and decision-makers with priority actions and options to enhance productivity, and combat land degradation to improve food security in the region.
\end{abstract}

Keywords: land use, food security, climate change, desertification, land restoration

\section{Introduction}

Impacts of land degradation and desertification (LDD) on livelihoods, environment, economic growth and migration are becoming more apparent throughout the Near East and North Africa region (NENA), a densely populated region with limited land and water resources for food production (Zdruli, 2014). NENA is home to about 410 million people, or $10 \%$ of the world's population (Croitoru and Sarraf, 2010) and despite arable land covers only $4.6 \%$ of the total land area (FAOSTAT, 2018), or about $0.142 \mathrm{ha} /$ per person (FAOSTAT, 2018), agriculture remains a vital socio-economic sector, contributing on average $14 \%$ to the Gross Domestic Product (GDP) (excluding oil producing countries) as well as generating jobs and incomes for $38 \%$ of the region's economically active population (FAO, 2017c).

Land degradation is also a natural and human-induced process that negatively affects the land's natural functions related to water, energy, nutrient storage, and recycling, leading to a decline in land productivity. The United Nations (UNEP, 1992) define desertification as "land degradation in arid, semi-arid and dry sub-humid regions resulting from various factors, including climatic variations and human activities". LDD affects in different ways about $86 \%$ of NENA's total area of 14.1 million $\mathrm{km}^{2}$ (Abahussain et al., 2002; FAO and ITPS, 2015). Growing populations and increased demand for agricultural products pose a tremendous pressure on soil and water 
resources and may trigger even more future reliance on imports in a region where many countries import even more than $50 \%$ of the consumed calories, exposing them to food insecurity and social unrest (Zdruli, 2014). Despite the importance of maintaining or increasing agricultural productivity, inappropriate policies and practices such as the conversion of fertile agricultural lands into other uses (including urbanization), mismanagement of government subsidies, land fragmentation, overgrazing, deforestation, and inappropriate irrigation and cultivation methods are some of the factors that contribute to the degradation of agricultural land and reduce its productivity over time. Furthermore, problems of wind and water erosion, sand and dust storms, nutrient depletion, salinization and sodification are increasingly affecting the productive capacity of the NENA soils (FAO and ITPS, 2015; FAO, 2019c). Climate change, socio-economic changes and conflicts further exacerbate these challenges (FAO, 2016b). The interaction between LDD, climate change, water scarcity and food security and how these affect migrations in NENA are important dimensions yet to be explored in detail.

NENA's regional cost of environmental degradation in 2010 ranged from 2.1 to $7.4 \%$ of the GDP for different countries (Croitoru and Sarraf, 2010) which is much higher when compared to 0.9\% of the average global environmental degradation in terms of GDP in 2008 (Hussein, 2008). Moreover, the cost of land degradation alone affects $1.62 \%$ of the NENA's GDP (Nkonya, et al., 2016).

A worldwide synthesis of meta-analyses suggests that a global median loss of $0.3 \%$ of annual crop yield occurs because of soil erosion, and warned that a total reduction of $10 \%$ loss could be projected for 2050 globally (FAO, 2019a). This yield loss due to continued soil erosion could be equivalent to the removal from crop production of 4.5 M ha $\mathrm{yr}^{-1}$ of agricultural soils (FAO and ITPS, 2015; FAO, 2019a). Comparing these data with the estimated soil erosion rates in NENA that are on average 1-2 orders of magnitude greater than rates of soil formation (Montgomery, 2007; Stockman et al., 2014), implies that the depletion of soil as a non-renewable resource could become extremely critical for the region (FAO and ITPS, 2015).

Nonetheless, there are also many opportunities to reorient these trends toward sustainability and resilience. Globally, it is estimated that over two billion hectares of land could be subject to restoration and rehabilitation through the application of sustainable land and water management (SLWM) techniques (World Resources Institute, 2014). SLM is defined as "the use of land resources, including soils, water, animals and plants, for the production of goods to meet changing human needs, while simultaneously ensuring the long-term productive potential of these resources and the maintenance of their environmental functions" (United Nations, 1992).

Throughout NENA there are roughly 3.5 million $\mathrm{km}^{2}$ of land potentially suitable for introducing SLWM practices in irrigated, rainfed and rangeland agroecosystems (Ziadat et al., 2014). Data from other regions such as South-East Asia, based on an assessment of the Economics of Land Degradation (ELD) (ELD, 2018) indicate that the benefits due to SLWM practices are worth about USD 3.01 billion, while acting against soil erosion in Africa could generate benefits of about USD 2.48 trillion (ELD and UNEP, 2018).

Nevertheless, proceeding with land restoration and reclamation requires the identification of areas suitable for introducing specific SLWM options, and creating an enabling environment to support farmers and land users in adopting these options. Furthermore, it is important to invest in capacity building, education, and awareness to establish and/or strengthen extension services, both public and private, and to create a political and economic environment that enables land users to implement SLWM. Experience has shown that it is only when local land users are put at the center of the land management and restoration interventions that success is achieved (Liniger and Chritchley, 2007, Ziadat et al., 2015). Based on these experiences, this paper provides examples of efforts and success stories from various countries in the NENA region. Moreover, these examples are needed to identify cost-effective solutions to support governmental legislation, policies, funding, and actions to curtail the costs of degradation, improve environmental conditions and the livelihoods of local people.

\section{Climate Change, Sustainable Development Goals (SDG) and Land Degradation Neutrality in NENA}

Human-induced land and soil degradation have affected the region for millennia (Zdruli et al., 2010; Zdruli, 2014), but recently they are gaining even more international attention. Soil is central for realizing 8 of the 17 SDGs, and the most important effect is on the large number of small-holder farmers in the poorest countries (Hou, 2020; Hou, et al., 2020). At the UN Framework Convention on Climate Change (UNFCCC, 2017) COP23, the role of soil and water management in combating climate change was acknowledged and included as a significant element in the Decision 4/CP.23 known as the Koronivia Joint Work on Agriculture.

Furthermore, the IPCC indicated that climate change exacerbates the rate and magnitude of several on-going land degradation processes and introduces new degradation patterns also emphasizing that both land degradation and climate change, individually and in combination, have profound implications for natural resource-based livelihood systems and societal groups (IPCC, 2019). At the same time land degradation is a driver of climate 
change through emission of greenhouse gases and reduced rates of carbon uptake. NENA is particularly sensitive to climate change and the North Africa and Middle East region in particular will become hotter and drier (Tuel and Eltahir, 2020).

Efforts are under way also in the context of the Nationally Determined Contributions (NDC) to climate change mitigation and adaptation as emphasized also by the COP26 of UNFCCC held in Glasgow in 2021. A global analysis indicates that the agriculture sectors (crops, livestock, forestry, fisheries, and aquaculture) are featured prominently in the NDCs and are among the foremost priorities in countries' mitigation contributions and adaptation objectives (FAO, 2017b). Eighty-nine percent of all countries and $86 \%$ of all developing countries refer to agriculture (crops and livestock) and/or land use, land-use change and forestry when outlining their mitigation contributions. Furthermore, $67 \%$ of all countries reveal climate-related hazards including extreme events, long-term impacts, and variability of climate phenomena as the most pressing issues when dealing with climate change. SLWM and land use planning remain the key tools identified by many countries to achieve climate change targets through the NDC process (FAO, 2018a). SLWM and its contribution to global environmental benefits in terms of climate and biodiversity are also well recognized and supported by several international agreements (GEF, 2018).

Countries of the NENA region expressed their commitments and actions to face the climate change challenges in the submitted NDC reports. Seventy five percent of the countries reported agriculture in their NDCs, while 56 and $44 \%$ included forestry and fisheries accordingly. Furthermore, $69 \%$ mention mitigation targets and/or actions, while $25 \%$ emphasize cropland management as a priority area for action and another $13 \%$ mention grazing land management as a priority (FAO, 2016b). The preparation of the new reporting on the NDCs for the countries of the region offers a good opportunity to emphasize the challenges of climate change on land resources and the measures needed for adaptation.

The SDG process, including its targets and indicators, is the strategic framework of the 2030 Agenda for Sustainable Development. There are several SDGs directly or indirectly linked to food security, natural resources management and planning. They relate to ending hunger and achieving sustainable agriculture (SDG 2) (Lipper et al., 2020); protecting and restoring water-related ecosystems, including mountains, forests, wetlands, rivers, aquifers, and lakes (SDG 6); protecting and restoring terrestrial ecosystems and promoting sustainable use of land (SDG 15), and combating climate change and its impacts (SDG 13). In the context of SDG 15 (Life on Land), and particularly target 15.3 "Protect and restore terrestrial ecosystems and promote sustainable use", the focus is on deploying tools and strengthening countries' capacities in regular data collection and analysis through appropriate methodologies and databases (Liniger et al., 2018).

The technical principles recommended by the Voluntary Guidelines for Sustainable Soil Management (VGSSM) are a good instrument to be implemented in NENA to enhance soil health and sustained food production. These include the following: (1) minimize soil erosion; (2) enhance soil organic matter content; (3) foster soil nutrient balance and cycles; (4) prevent, minimize and mitigate soil salinization and alkalinization; (5) prevent and minimize soil contamination; (6) prevent and minimize soil acidification; (7) preserve and enhance soil biodiversity; (8) minimize soil sealing; (9) prevent and mitigate soil compaction; and (10) improve soil water management (FAO and ITPS, 2017).

At the Rio+20 Summit, the world's leaders committed to achieve a land degradation neutral world in the context of sustainable development. Land Degradation Neutrality (LDN) is defined as "a state whereby the amount and quality of land resources necessary to support ecosystem functions and services and enhance food security remain stable or increase within specific temporal and spatial scales and ecosystems". The goal of LDN is to maintain or enhance the land resource base - the stocks of natural capital associated with land resources and the ecosystem services that flow from them (UNCCD-GM, 2016; Akhtar-Schuster et al., 2017; Orr et al., 2017; Liniger et al., 2018). UNCCD-GM (2016), within its LDN Target Setting Program, developed a technical guide on how to define national baselines, identify voluntary targets and associated measures to achieve LDN by 2030 and monitor progress towards LDN targets.

The situation across NENA in terms of LDN reporting vary from country to country, with some like Morocco, Egypt, and Tunisia in an advanced stage, while others like Syria and Libya far behind due to their difficult political situations. Efforts are under way by the League of Arab States and the Council of the Arab Ministers of Environment (CAMERE) and the Arab Organization for Agricultural Development to enhance the LDN process throughout the region. The High-level Political Forum (HLPF) of the United Nations, as a central platform for follow-up and review of the 2030 Agenda for Sustainable Development and the Sustainable Development Goals, has set forward a well-defined and clear outline to meet the SDGs. This includes SDG 1 (no poverty), 2 (zero 
hunger), 3 (good health and well-being), 8 (decent work and economic growth), 10 (reduced inequalities), 12 (responsible consumption and production), 13 (climate action), 16 (peace, justice, and strong institutions), and 17 (partnerships). This operational framework is also very relevant for NENA.

\section{Land Resources, Sustainable Agriculture and Food Security in NENA}

Globally, one-third of the land used for agriculture is moderately to highly degraded (FAO and ITPS, 2015) but the population in dryland areas is most vulnerable to resource base degradation. Furthermore, it is estimated that food production will need to increase from the current 8.4 billion tons to almost 13.5 billion tons a year to feed a population projected to reach 9.3 billion in 2050 (FAO, 2017e). While the prevalence of malnourishment in NENA has remained stable over the past decade, the region suffers from higher average rates of undernourishment than any other global region aside from Sub-Saharan Africa. Even in stable NENA countries, malnutrition generally ranges between $5-10 \%$ of the population (FAO, 2017b). LDD and unstable political situations in several countries impedes the overall strategic objective of achieving food security and reducing hunger. In addition, desertification is nowhere more serious than in the NENA region. Under these circumstances, opportunities for horizontal agricultural expansion are either diminishing or does not exist in many countries, leaving few options available for most of them: i) using the remaining arable lands sustainably and/or ii) rehabilitating and bringing back degraded lands into the production system. Nonetheless, reducing food waste, mostly due to post-harvest losses and improving green and blue water management could be viable options as well.

Unsustainable land use patterns are among the most important drivers of LDD. Using the land without properly considering the limitations and potentials of resources (soil, water, landscape, vegetation, climate, livestock, forest resources and human activities) enhances its vulnerability and risk for degradation (FAO, 2017b). Unfavourable climatic conditions (imposed also by climate change/variability) coupled with mismanagement of resources leads to degradation and vulnerability, while favorable human activities, such as selecting proper land use types and implementing SLWM practices will enhance sustainability and resilience. However, the actual extent of LDD in NENA needs to be more accurately estimated to support realistic and responsive land use planning. Fana et al. (2021) stated various options to cope with farmers' vulnerability: improve rural infrastructure and facilities, devising an effective and responsive institutional setup for enhancing the capacities of smallholder farmers in the short-run and minimizing the likelihood of exposure and sensitivity in the long-run.

\section{Drivers and Processes of Land Degradation and Desertification}

The relationships between different direct and indirect drivers of LDD and the impacts from and on climate change, food security and migration are complex in the NENA region. As shown in Figure 1, factors related to natural processes and socio-economic conditions are causing accelerated soil degradation, which together with degradation and scarcity of other natural resources lead to accelerated LDD. LDD is additionally driven by climate change and conflicts and exacerbated by migration and food insecurity. Most of the processes and their dynamics represented as arrows, are reversible. Therefore, combating LDD is possible by tackling the drivers, through implementing proper SLWM practices, which will also reverse the adverse patterns in natural resource depletion, livelihoods, resilience, food security, and migration. 


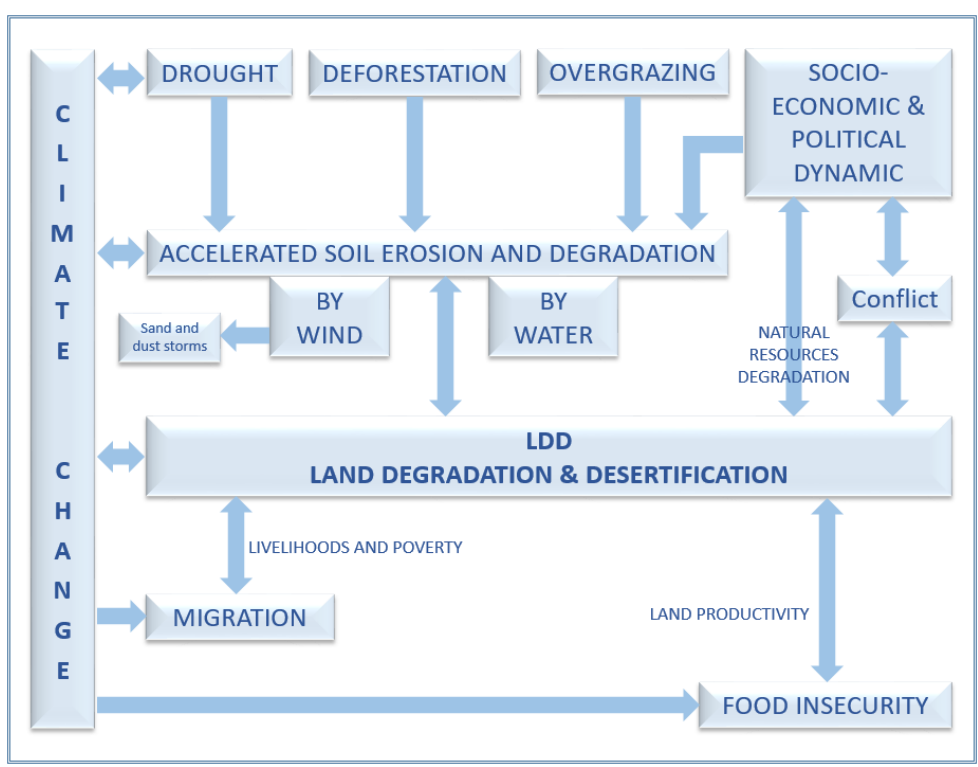

Figure 1. Land degradation, climate change, food security and migration nexus in the NENA region

NENA is affected by different land use practices and land related processes that accelerate land degradation. Soil erosion by water and wind including sand and dust storms (SDS), drought, overgrazing, deforestation merged with socio-economic and political dynamics, including urbanization, are amongst the burning issues in the region and are briefly presented below.

Soil erosion by water is caused by improper land use and management, especially in hilly areas and sloping agricultural lands. Continuous cultivation of arable lands, exploitative tillage practices (up and down the slope), absence of intercropping and crop rotations and destruction of vegetation cover contribute to soil erosion (Also, the soil physical properties are an important aspect to consider). Consequently, soil nutrient losses and organic carbon followed by decline in crop productivity and diminished ecosystem services are some of the consequences of erosion. Since 2002, Abahussain et al., (2002) identified the following countries as the most affected by water erosion in NENA, arranged in order of surface area affected: Iran, Sudan, Yemen, Algeria, Tunisia, Morocco, Oman, Libya, Syria and Iraq (FAO and ITPS, 2015). To reverse the situation, there is an urgent need to move from assessments to collective actions and solutions in consensus with all stakeholders across the region.

Soil erosion by wind is another severe process since more than half of the NENA region receives on average an annual rainfall of less than $150 \mathrm{~mm}$, vegetation growth is limited, and soil organic matter is very low. Therefore, approximately 60\% (or 135 million ha) of soil is eroded by wind (FAO and ITPS, 2015) and this results in dust storms under certain conditions. The following countries are the most affected by wind erosion, arranged in order of surface area affected: Sudan, Saudi Arabia, Libya, Iran, Algeria, Yemen, Tunisia, Syria, Iraq, Jordan, and Egypt. It should be noted that NENA is among the most affected regions from SDS; as the region loses about USD 13 billion in GDP every year due to dust storms (FAO, 2018b). There has been a significant increase in the frequency, intensity, scale and geographical coverage of SDS in the past 15 years. The increased frequency and intensity of SDS in the region, if not counteracted, may jeopardize livelihood systems in affected areas, leading to escalated movement of rural people from their home areas (FAO, 2018b). To respond to current and future threats of SDS, monitoring dust emissions, and further research is critical to ensure informed decision-making both in the short and long-term. There is a need to build national capacity in SDS preparedness and emergency response across sectors. Prevention and mitigation measures on the local level that promote sustainable land and water management are also essential to mitigate the negative effects of SDS. The cyclic nature of the process and the transboundary geographic complexity call for urgent collective and regionally-based actions. Furthermore, both wind and water erosion rates are dependent on the weather. Therefore, linkages between land degradation and climate change are particularly important in NENA.

Drought: Severe droughts are becoming more frequent especially in Iraq, Jordan, Morocco, and Syria. For instance, the severe drought of the period 1998-2001 was the worst in the last 30 years (FAO, 2018c). This caused the reduction of cereal production in Syria and Jordan by $40 \%$ and loss of animal production by $35 \%$. 
Because of the drought, Morocco and Tunisia were forced to import large amounts of cereals to meet the food demands of the population, and Mauritania faced significant increases in food and feed commodity prices (FAO, 2018a).

The LDD process is cyclic and interlinked. For instance, a major problem facing Morocco is the impact of climate change and the increased prevalence of drought. With most farmland located in areas that receive less than $400 \mathrm{~mm}$ of rainfall each year, this has serious implications. These prolonged droughts are increasing soil degradation, with desertification threatening $80 \%$ of land, and soil erosion affecting nearly half of it (Sustainable Food Trust, 2015).

Overgrazing is another important driver of land degradation in the NENA region as it reduces land productivity, accelerates water and wind erosion causing the loss of vegetation cover and soil organic carbon. The process is accentuated by the unregulated movement of herds and uncontrolled grazing often across the political borders of neighboring countries. The growing population and the increasing demand for red meat has led to significant increases in the numbers of livestock. This has led in turn to rapid degradation of rangelands in most NENA countries. It is estimated that average vegetation cover as a percentage of land area in the region decreased from $3.7 \%$ in 1990 to $2.8 \%$ in 2013, while livestock numbers increased in the same period by $25 \%$ (FAO, 2016b). The provision of subsidies to farmers and herders has unintentionally encouraged larger herds than the land can support.

Deforestation rates in NENA are high in comparison with the region's limited forest cover (41 531220 hectares). During the period 1990-2020 NENA experienced a net loss of forest cover of 6 percent and other wooded lands recorded a 15\% decline during the same period (FAO, 2021). Information about extent, severity and impact of deforestation, overgrazing and rangeland conditions remains largely unknown and further research is needed, especially at landscape/local level.

Urbanization. The most fertile land especially in Egypt is under continuous loss by urbanization with severe destruction of the country's limited agricultural land. Over the last three decades, significant losses in agricultural land were observed together with a remarkable growth in the urban area. It is estimated that agricultural land has decreased by $11.03 \%$ in some areas east of the Nile Delta (El-Kawy et al., 2010).

Socio-economic and political dynamics are strictly related to land degradation rates. Conflict has become a dominant feature of the NENA region, with continued outbreaks of violence occurring in several countries (FAO, 2017c). The region had over 14 million internally displaced persons in 2017 in addition to 6.7 million refugees fleeing NENA countries in 2016 (FAO, 2017c). Countries such as Jordan and Lebanon that host about 46\% of all refugees in the region bear substantial pressure on their natural resources, including land and water. Countries under conflicts also suffer from land abandonment. In addition to being one of the main causes of migration (FAO, 2017c), land degradation contributes to worsening hunger, food insecurity and malnutrition in the region, especially due to the ongoing conflicts and crises in Yemen, Iraq, Syria, Sudan, and Libya.

Migration: Land degradation and climate change interact with other processes in ways that undermine the sustainability of household livelihoods and increases the likelihood of migration (IPBES, 2018). Examples show a complex picture when land degradation has caused migration, and on the other hand, where migration has caused or exacerbated land degradation (Mcleman, 2017). Migration rates from 12 out of 20 NENA countries have increased significantly since 2010. Additional research has shown that in Morocco, Tunisia, Lebanon, Syria and Palestine, migrants represent over 10\% of the total population (Fargues, 2017).

Conflict in the region is an important cause of migration. However, migration is also triggered by limitations of land and water resources, reduction in land productivity and climate change (rainfall and temperature). High migration rates from non-conflict zone countries have been influenced by environmental resource depletion or degradation. Water scarcity is expected to impact 80-100 million people in the region by 2025, while LDD significantly accelerates migration. Unless concerted regional collaboration for tackling the drivers of LDD are taken, it will result in a worsening situation.

Other migration push factors such as weak social protection programs in NENA may aggravate land abandonment, thus degradation. It is known that social protection can influence rural migration patterns in several ways, as it addresses the multidimensional nature of poverty, one of the main drivers of migration. Social protection programs are important in addressing poverty and food insecurity. Only $16 \%$ of the poorest of the region's population receives any form of social protection. In addition, the political economy of social protection often influences its delicate framework: as revenues come from national governments, hence, the creation or even expansion of social protection depends on government willingness. 
Emerging technologies such as social media, smart phones, services, and apps might offer opportunities to counter land degradation and enhance sustainability. Participatory monitoring of resources through communication and feedback to extension and advisory personnel are becoming increasingly easier. These could be used in conjunction with available databases on best practices to inform the decision-makers and the public about viable options for specific conditions through an informal or private advisory system.

\section{Opportunities}

Due to the urgency and relevancy to reverse LDD, options are available to avoid further degradation and to support the restoration of already degraded lands in several NENA countries. A very efficient method is land use planning, a key tool to support decision-makers at various levels and guide the allocation of land resources to optimum uses. But the role of land use planning is not fully exploited due to various factors, such as the lack of data/information to support decision-making, availability of user-friendly tools for planning, absence of political will, lack of readily available approaches to integrate and harmonize biophysical and socio-economic decision-support systems, and information needed for effective planning, management and policy-making. Countries are being supported by various UN agencies and International Development Agencies to tackle these challenges with specialized tools and methods developed for spatial and non-spatial information collection, analyses, and mapping land management and degradation at multiple scales (Ziadat et al., 2021; FAO Land Resources Planning Toolbox, 2019b).

Integrated landscape management and land resource planning approaches are key tools implemented for promoting SLWM. The following are some examples that have been implemented in Morocco, Palestinian Authority, Sudan, Tunisia and in the mountainous areas of Oman and Yemen and include: integrated watershed management; community territorial development; forest landscape restoration; sustainable land management; (agro) ecosystem approach; land evaluation and land use planning (Ziadat et al., 2021). The United Nations General Assembly declared 2021 - 2030 the UN Decade on Ecosystem Restoration that offers unique opportunity for restoring degraded land and halting desertification, contributing positively to food security in the region.

\section{Immediate Actions to Promote SLWM in NENA}

Immediate actions to promote interventions and provide an enabling environment to enhance SLWM and restoration activities include the following: control overgrazing, keep soil salinity under control, combat sand and dust storms, enhance drought preparedness and adaptation, control erosion and promote climate smart agriculture, and regenerative agriculture, even in countries where these types of agriculture are almost unknown.

Promising SLWM options are available to reverse land degradation such as the one implemented in the Kagera Basin in Africa (FAO, 2017d). A guiding flexible approach is proposed to reverse land degradation by identifying target areas where adaptable SLM options have high potential of success. This is possible when coupled with an implementation and scaling out approach supported by proper policies and financial mechanisms. However, to reach success it requires continuous monitoring and evaluation to assess the impact and guide fine-tuning based on future fluctuations to be able to adjust the decision-making process (FAO, 2017c).

In that context several methods and approaches could be mentioned. An example is the Great Green Wall of Africa (Figure 2) that provides an example of land restoration needs and opportunities with the aim of catalysing action to increase the resilience of people and landscapes to climate change. 


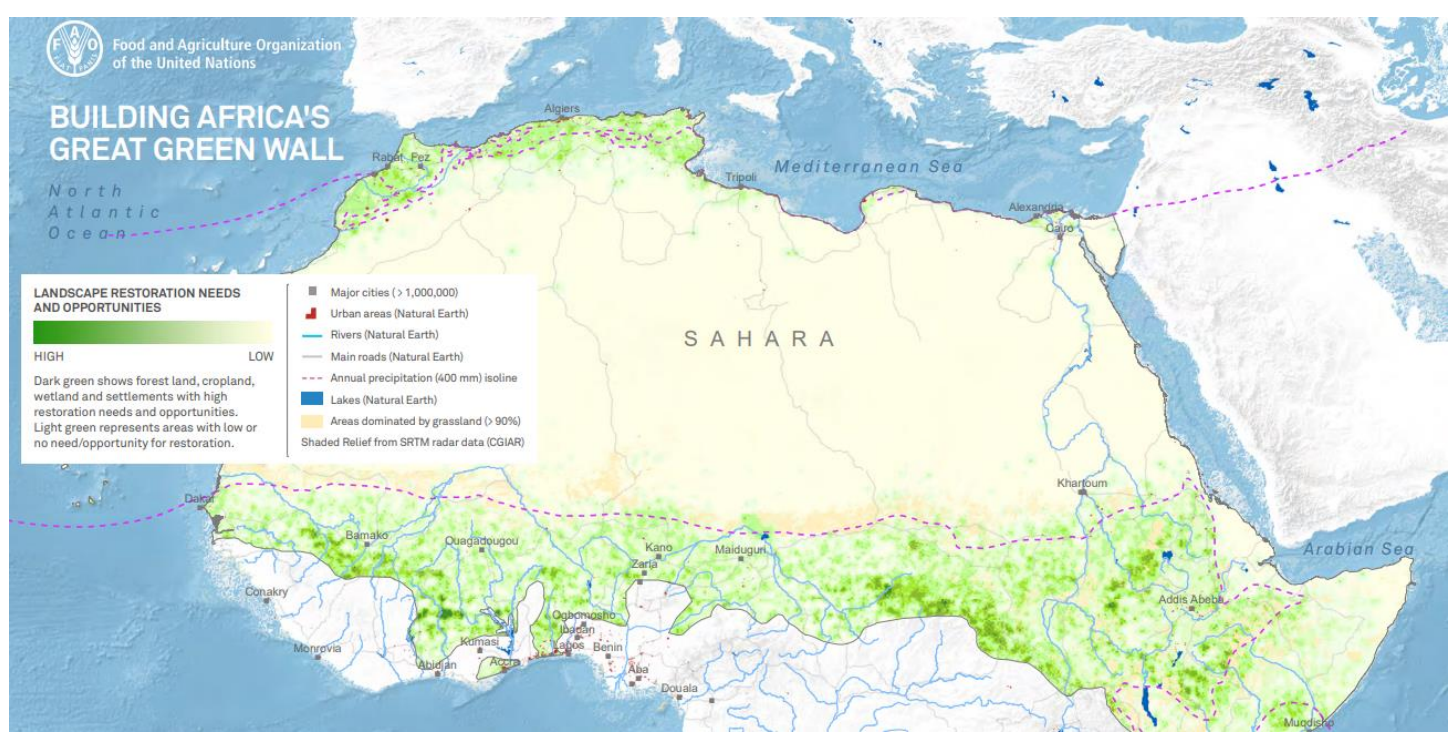

Figure 2. Mapping of restoration needs and opportunities in Africa

Source: Berrahmouni et al., 2016

http://www.greengrowthknowledge.org/sites/default/files/downloads/resource/FAO_Great_Green_Wall.pdf

Another complementary analysis is provided by the similarity assessment (Figure 3) to identify potential areas for scaling out SLWM options (Ziadat et al., 2015). Identifying land restoration potential, similarity and suitability analyses should support the decision-making process to identify and prioritize areas for immediate actions at regional, national, and local levels. New cost-effective and time efficient methods for land suitability assessment should be used to enhance the widespread use of land suitability in land use planning (MahmoodiEshkaftaki, et al., 2020). Finally, the selection of proper technologies and practices should be guided by local, national, and regional experience and global SLWM knowledge platforms (Liniger and Critchley, 2007; Schwilch et al., 2011; Harari et al., 2017). In order to support countries in assessing the sustainability of the management practices, the FAO Global Soil Partnership released a protocol for the assessment of sustainable soil management (FAO and ITPS, 2020).

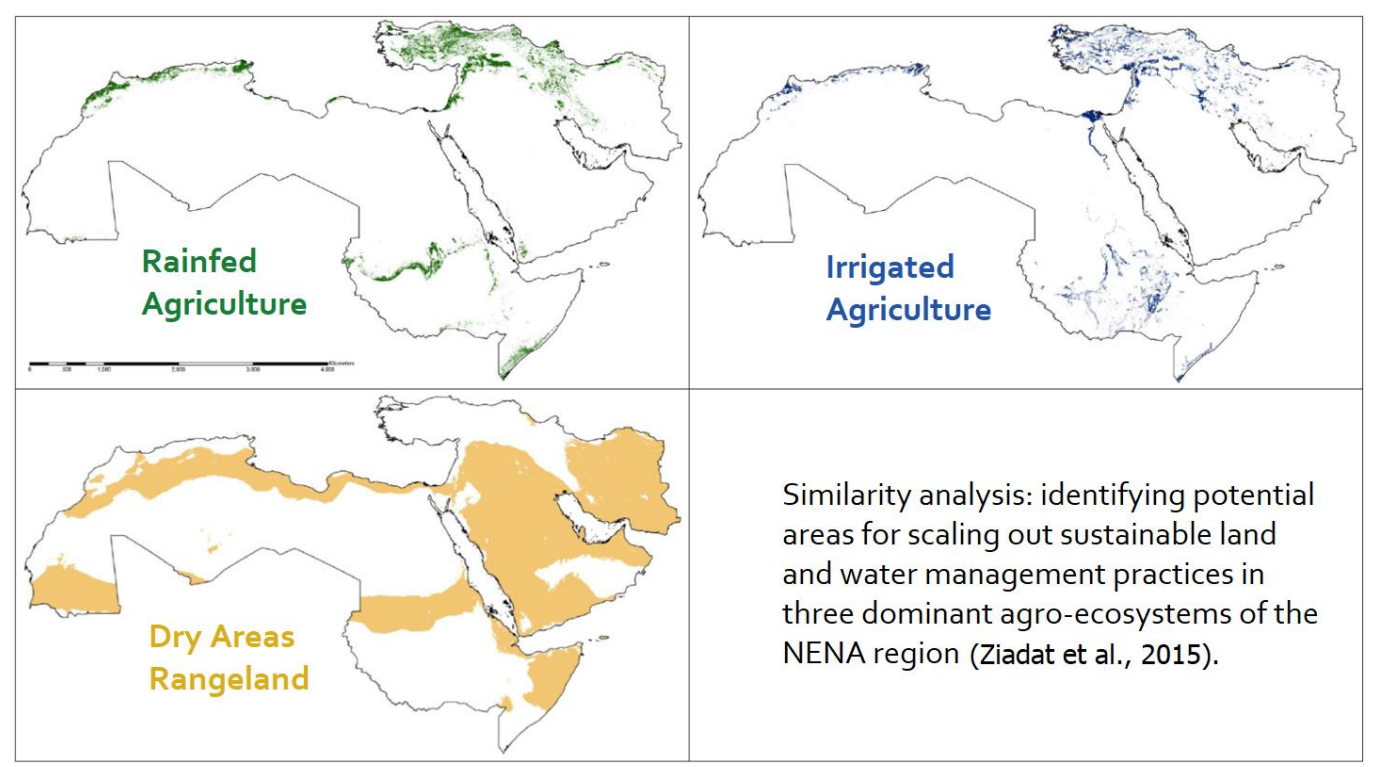

Figure 3. Similarity assessment to identify potential areas for scaling out sustainable land and water options Source: https://repo.mel.cgiar.org/handle/20.500.11766/8856 


\section{Investment Opportunities for SLWM in NENA}

The Economics of Land Degradation Initiative (ELD, 2018) offers a global platform that helps to create the economic evaluation of SLWM. This is supported by research, capacity development and knowledge exchange to ensure that these economics are comprehensively mediated and appropriately implemented to highlight the value of land and its terrestrial ecosystems and services provided to society.

The key challenge is to define at which stage to intervene and what level of finance to invest. It is essential to distinguish between different degrees of LDD and the resulting cost of intervention at each stage. Prevention of LDD is the first stage, before degradation occurs, whereas reduction is the second stage where degradation is on-going. Restoration is the third stage where land has already been degraded (Figure 4). Intervening sooner allows prevention or reduction to be carried out with lower cost and better results. Waiting for land to become severely degraded, allows only the option of restoration, often at very high cost.

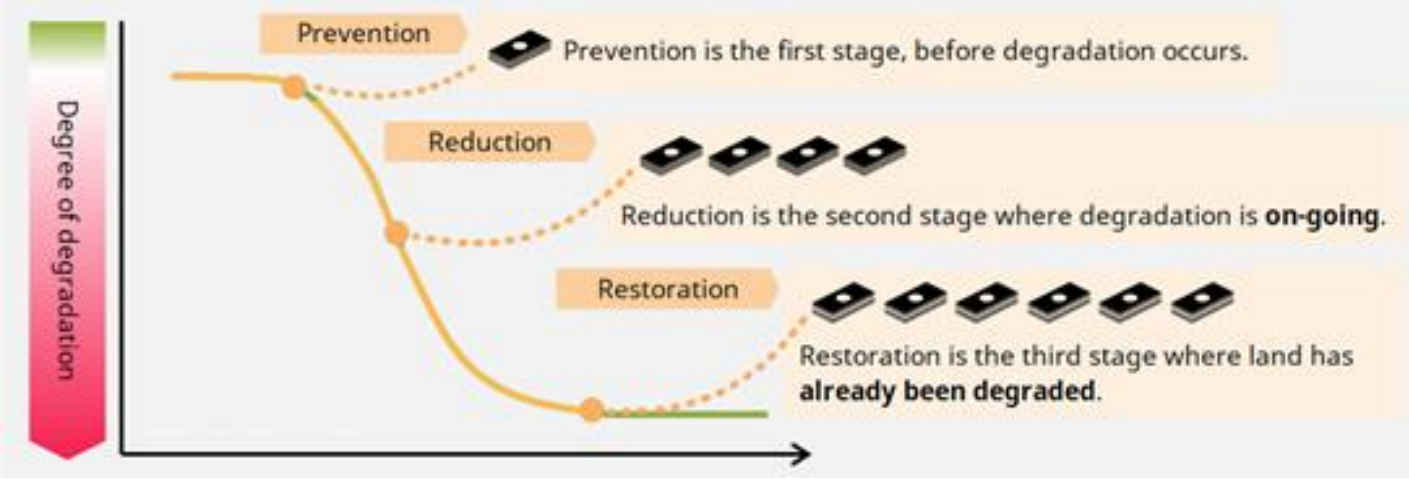

Figure 4. Costs of land degradation and remediation actions

Source: Sustainable Land Management and Restoration, (modified from ELD, 2018).

The cost-benefit analysis compares the costs of adopting a SLWM practice against the benefits derived from it, in order to determine its net economic benefit. Conducting this analysis with different scenarios can help determine which is optimal. The economics of land degradation assessment for Asia (ELD and UNEP, 2018) concluded that benefits through SLWM investments are worth about USD 3,01 billion, equal to USD 6,182 per ha with a benefit cost ratio of about 3.5. To use a NENA region example, in Jordan it is estimated that if the "Hema" traditional practice of managing common land is adopted within the Zarqa River Basin, it could deliver USD 203-408 million of net-benefits through carbon sequestration, increased water infiltration and reduced sediments.

\section{Planning, Monitoring and Knowledge Sharing}

Focusing on the scaling-out of SLWM practices is indispensable to generate tangible positive impacts on the environment, food security and livelihoods. A comprehensive view is needed to consider the barriers that hinder adoption and scaling out of SLWM and to enhance an overall enabling environment that support this process. In particular, the "human" dimension and participatory land use planning approaches (as compared to the bio-physical assessments) needs to be further considered and elaborated. It is very crucial to share knowledge with small-holders and users in these areas to help them to adopt sustainable soil use and management practices (Hou, 2020).

Land use planning is part of the integrated land resources management continuum that starts with assessments of the land resource base followed by identification of needs and challenges, and finally by the selection and implementation of the best SLWM practices. This procedure is described by Figure 5, designed to inform decision-makers and stakeholders on the actions to be taken (Ziadat et. al., 2021). The guiding principles of land use planning places people at the centre of the process that also includes governance, enabling policies and institutions needed to implement sustainable land use planning. These actions are currently implemented or in the process of being implemented in many NENA countries (Zdruli, 2014). 


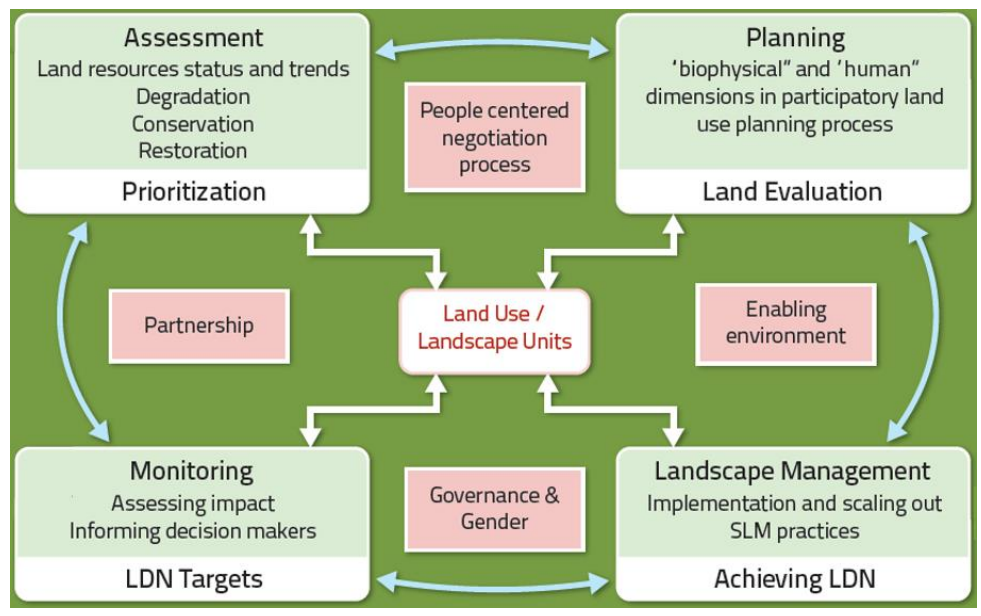

Figure 5. Four inter-related steps in the integrated land resources management continuum

The implementation process includes the development of standardized indicators and tools for assessing and monitoring the status of LDD and then collating this information to generate standard tools and approaches. The aim is to support the sustainable management of land resources through assessment, planning and implementation and to align these with the LDN and with NDC processes (FAO, 2018a) to support countries in achieving and reporting LDN and climate action targets (Figure 6).

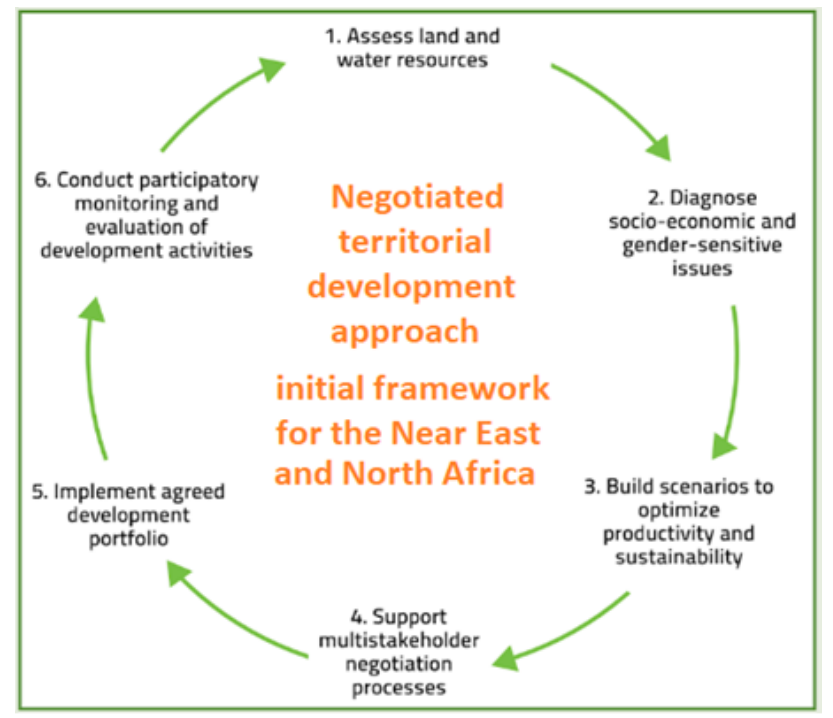

Figure 6. Negotiated territorial development approach - an initial framework for the NENA (FAO, 2016a)

\section{Conclusions}

Due to its large extent, great diversity of natural, socio-economic and political conditions, the NENA region is very complex. The bottom-up approach that puts people at the centre of ecosystems and proposes the development and implementation of good SLWM options is essential to achieve sustainable management of land and water resources and achieving LDN targets in particular and SDGs in general.

The most important conclusions and recommendations of this paper are tailored to provide a comprehensive package that could support sustainable management of precious and scarce land and water resources under harsh environmental and socio-economic conditions in NENA. These include: 
- Analysis of the "land degradation - climate change - water scarcity - food security - migration" nexus to tackle the challenges and find sustainable options at different scales is needed to enhance sustainable use and management of limited land and soil resources of NENA.

- Promote the scaling-out of sustainable management options supported by appropriate and site-specific tailor-made policies to be able to enhance productivity and livelihoods.

- Investing in "land", accompanied with a need to provide knowledge on the costs and benefits of SLWM and to encourage investments by the private and public sectors.

- Enhance the governance of land and water resources and support sustainable management, access and tenure.

- Support transformations from degradation and vulnerability to sustainability and resilience. Tools and approaches should be promoted to assess, plan, manage, and monitor natural resources and to inform the decision-making process through a knowledge management and sharing platform.

Finally, enhancing land and water productivity and sustainability, combating land degradation, and coping with water scarcity are crucial for achieving food security, sustainable agriculture, and the SDGs. Options to enhance sustainable land and water management provide promising solutions. However, participatory planning across sectors and landscapes to identify potential solutions, coupled with proper enabling environment and support from policies, governance, and financial/investment mechanisms, are needed in order to enhance food production and sustainability of limited resources.

\section{Statement}

The views expressed in this publication are those of the author(s) and do not necessarily reflect the views or policies of the Food and Agriculture Organization of the United Nations.

\section{Acknowledgments}

The authors would like to acknowledge the contribution of Abdel Hamied Hamid, Eduardo Mansur, Faten Adada, and Stephan Baas for their valuable contribution to this article.

\section{References}

Abahussain, A. A., Abdu, A. Sh., Al-Zubari, W. K., El-Deen, N. A., \& Abdul Raheem, M. (2002). Desertification in the Arab region: analysis of current status and trends. J. Arid Environ., 51, 521-545. https://doi.org/10.1006/jare.2002.0975

Akhtar-Schuster, M., Stringer, L. C., Erlewein, A., Metternicht, G., Minelli, S., Safriel, U., \& Sommer, S. (2017). Unpacking the concept of land degradation neutrality and addressing its operation through the Rio Conventions, Journal of Environmental Management, 195, 4-15. https://doi.org/10.1016/j.jenvman.2016.09.044

Berrahmouni, N., Laestadius, L., Martucci, A., Mollicone, D., Patriarca, C., \& Sacande, M. (2016). Building Africa's Great Green Wall. Restoring degraded drylands for stronger and more resilient communities. Food and Agriculture Organization of the United Nations.

Croitoru, L., \& Sarraf, M. (2010). Measuring the Cost of Environmental Degradation. In L. Croitoru \& M. Sarraf (Eds.), The cost of environmental degradation: case studies from the Middle East and North Africa. The World Bank, Washington DC. https://doi.org/10.1596/978-0-8213-8318-6

El-Kawy, O. R. A., Ismail, H. A., Rod, J. K., \& Suliman, A. S. (2010). A developed GIS-based land evaluation model for agricultural land suitability assessments in arid and semi arid regions. Research Journal of Agriculture and Biological Sciences, 6(5), 589-599.

ELD. (2018). Economics of Land Degradation Initiative. The Economics of Land Degradation Initiative. Retrieved from http://www.eld-initiative.org/index.php?id=1

ELD and UNEP. (2018). The Economics of Land Degradation Neutrality in Asia and Africa. Retrieved from http://www.eld-initiative.org/fileadmin/pdf/Asia_Report_EN.pdf

Fana, C., Haji, J., Jaleta, M., Ademe, A., \& Gebresenbet, G. (2021). Vulnerability of farmers to crop farming risks in Ethiopia: an integrated vulnerability analysis approach using social-ecological system framework. Sustainable Agriculture Research, 10(3), 25. https://doi.org/10.5539/sar.v10n3p25

FAO. (2015). World Soil Charter. Retrieved from http://www.fao.org/3/a-i4965e.pdf

FAO. (2016a). Negotiated territorial development in a multi-stakeholders participatory resource planning 
approach: an initial sustainable framework for the Near East region. Land and Water Division Working Paper No. 15. Rome.

FAO. (2016b). Near East and North Africa Regional Overview of Food Insecurity 2016. Cairo, pp. 35.

FAO. (2017a). Voluntary Guidelines for Sustainable Soil Management. Food and Agriculture Organization of the United Nations Rome, Italy.

FAO. (2017b). Intended national contributions: global analyses and key findings. FAO Rome, Italy. Retrieved from www.fao.org/3/a-i6573e.pdf

FAO. (2017c). Near East and North Africa Regional Overview of Food Insecurity 2016. Cairo. pp. 35

FAO. (2017d). Sustainable Land Management (SLM) in practice in the Kegara Basin. Land and Water Division. Food and Agriculture Organization of the United Nations: Rome, Italy

FAO. (2017e). The future of food and agriculture: trends and challenges. Food and Agriculture Organization of the United Nations: Rome, Italy. Retrieved from http://www.fao.org/3/a-i6583e.pdf

FAO. (2018a). Regional analyses of the Nationally Determined Contributions of countries in Southern-Eastern Europe and Central Asia: Gaps and opportunities in the agriculture sectors. Retrieved from http://www.fao.org/3/CA2518EN/ca2518en.pdf

FAO. (2018b). FAO Regional Conference for the Near East Thirty-fourth Session Side Event: The Challenge of Sand and Dust Storms in the Near East and North Africa Region. Retrieved from http://www.fao.org/fileadmin/user_upload/bodies/NERC_34/NERC34_SideEvents/MW769_SE_Challenge/ MW769_NERC_18_CONCEPT_NOTE_SDS_en.pdf

FAO. (2018c). Drought characteristics and management in North Africa and the Near East. FAO Water Reports 45. Food and Agriculture Organization of the United Nations Rome, Italy.

FAO. (2019a). Soil erosion: the greatest challenge to sustainable soil management. Rome. Licence: CC BY-NC-SA 3.0 IGO. p. 100. Retrieved from

http://www.iamb.it/uploads/attachments/794/web_Sustainable_land_management_and_land_restoration.pdf

FAO. (2019b). Land Resources Planning Toolbox, User's Guide. Retrieved from http://www.fao.org/3/ca5491en/ca5491en.pdf

FAO. (2019c). The Multi-Faced role of Soil in the Near East and North Africa Region - Policy Brief. Rome. Licence: CC BY-NC-SA 3.0 IGO. p. 36.

FAO. (2021). Near East and North Africa Regional Forest Resource Assessment 2020 - Extent, changes and trends. Cairo. https://doi.org/10.4060/cb7174en

FAO and ITPS. (2015). Status of the World's Soil Resources. Retrieved from http://www.fao.org/3/a-i5199e.pdf

FAO and ITPS. (2017). Voluntary Guidelines for Sustainable Soil Management. Retrieved from http://www.fao.org/3/a-bl813e.pdf

FAO and ITPS. (2020). Protocol for the assessment of Sustainable Soil Management. Rome, FAO. Retrieved from http://www.fao.org/fileadmin/user_upload//GSP/SSM/SSM_Protocol_EN_006.pdf

FAOSTAT. FAO's global statistical database on food and agriculture. Retrieved from http://www.fao.org/faostat/en/\#data

Fargues, P. (2017). International Migration and the Nation State in Arab Countries. Middle East Law and Governance, 5, 5-35. https://doi.org/10.1163/18763375-00501001

GEF. (2018). GEF-7 Replenishment Programming Directions. Global Environment Facility. Fourth Meeting for the Seventh Replenishment of the GEF Trust Fund. Stockholm, Sweden. Retrieved from https://www.thegef.org/sites/default/files/council-meeting-documents/GEF-7\%20Programming\%20Directio ns\%20-\%20GEF_R.7_19.pdf

Harari, N., Gavilano, A., \& Liniger, H. P. (2017). Where people and their land are safer: A Compendium of Good Practices in Disaster Risk Reduction. Bern and Lucerne, Switzerland: Centre for Development and Environment (CDE), University of Bern, and Swiss NGO Disaster Risk Reduction (DRR) Platform, with Bern Open Publishing.

Hou, D. (2020). Knowledge sharing and adoption behaviour: An imperative to promote sustainable soil use and management. Soil Use and Management, 36(4), 557-560. https://doi.org/10.1111/sum.12648 
Hou, D., Bolan, N. S., Tsang, D. C. W., Kirkham, M. B., \& O'Connor, D. (2020). Sustainable soil use and management: An interdisciplinary and systematic approach. Science of the Total Environment, 729. https://doi.org/10.1016/j.scitotenv.2020.138961

Hussein, M. A. (2008). Costs of environmental degradation: An analysis in the Middle East and North Africa region. Management of Environmental Quality: An International Journal, 19(3), 305-317. https://doi.org/10.1108/14777830810866437

IPBES. (2018). Summary for policymakers of the thematic assessment report on land degradation and restoration of the Intergovernmental Science-Policy Platform on Biodiversity and Ecosystem Services. L. Montanarella, R. Scholes \& A. Brainich (Eds.), Bonn: IPBES Secretariat. Retrieved from www.ipbes.net/assessment-reports/ldr

IPCC. (2019). Climate Change and Land. Summary for Policy Makers. Retrieved from https://www.ipcc.ch/site/assets/uploads/2019/08/Fullreport.pdf

Liniger, H. P., \& Critchley, W., (Eds.). (2007). Where the land is greener - case studies and analysis of soil and water conservation initiatives worldwide. World Overview of Conservation Approaches and Technologies (WOCAT). p. 364.

Liniger, H., Harari, N., Fleiner, R., \& van Lynden, G. (2018). Achieving land degradation neutrality: the role of knowledge sharing and evidence-based decision-making. Questionnaires on Sustainable Land Management (SLM) Technologies and Approaches: A tool to help document, assess, and disseminate SLM practices. World Overview of Conservation Approaches and Technologies (WOCAT). https://doi.org/10.1016/j.envsci.2019.01.001

Lipper, L., DeFries, R., \& Bizikova, L. (2020). Shedding light on the evidence blind spots confounding the multiple objectives of SDG 2. Nat. Plants, 6, 1203-1210. https://doi.org/10.1038/s41477-020-00792-y

Nkonya, E., Mirzabaev, A., \& von Braun, J. (Eds.). (2016). Economics of land degradation and improvement- $A$ global assessment for sustainable development. Spinger Cham Heildelberg New York Dordrecht London. https://doi.org/10.1007/978-3-319-19168-3

Mcleman, R. (2017). Migration and land degradation: Recent experience and future trends. Global Land Outlook Working Paper. UNCCD, Bonn, Germany.

Mahmoodi-Eshkaftaki, M., Haghighi, A., \& Houshyar, E. (2020). Land suitability evaluation using image processing based on determination of soil texture-structure and soil features. Soil Use and Management, 36(3), 351-355. https://doi.org/10.1111/sum.12572

Montgomery, D. R. (2007). Soil erosion and agricultural sustainability. Proc Natl Acad Sci USA, 104(33), 13268-72. https://doi.org/10.1073/pnas.0611508104

Orr, B. J., Cowie, A. L., Castillo Sanchez, V. M., Chasek, P., Crossman, N. D. ... Welton, S. (2017). Scientific Conceptual Framework for Land Degradation Neutrality. A Report of the Science-Policy Interface. United Nations Convention to Combat Desertification (UNCCD), Bonn, Germany. https://doi.org/10.1016/j.envsci.2017.10.011

Schwilch, G., Bestelmeyer, B., Bunning, S., Critchley, W., Herrick, J., ... Winslow M. (2011). Experiences in Monitoring and Assessment of Sustainable Land Management. Land Degradation \& Development, 22(2), 214-225. https://doi.org/10.1002/ldr.1040

Stockman, U., Minasny, B., \& McBratney, A. B. (2014). How fast does soil grow? Geoderma, 216, 48-61. https://doi.org/10.1016/j.geoderma.2013.10.007

Sustainable Food Trust. (2015). Moroccan agriculture: Facing the challenges of a divided system. Retrieved from https://sustainablefoodtrust.org/articles/moroccan-agriculture-facing-challenges-divided-system/

Tuel, A., \& Eltahir, A. B. (2020). Why Is the Mediterranean a Climate Change Hot Spot? Journal of Climate, 33(14), 5829-5843. https://doi.org/10.1175/JCLI-D-19-0910.1

World Resource Institute. (2014). Atlas of Forest and Landscape Restoration Opportunities. Retrieved from https://www.wri.org/resources/maps/atlas-forest-and-landscape-restoration-opportunities

UNCCD-GM. (2016). Achieving Land Degradation Neutrality at the country level - Building blocks for LDN Target Setting. Bonn, Germany: Global Mechanism (GM) of the United Nations Conventions to Combat Desertification (UNCCD). Retrieved from https://www.unccd.int/publications/achieving-land-degradation-neutrality-country-level-building-blocks-ldn 
-target-setting

UNEP. (1992). The Status of Desertification and Implementation of the United Nations Plan of Action to Combat Desertification. Nairobi: UNEP.

UNFCCC. (2017). Decision -/CP.23. Koronivia Joint Work on Agriculture. Retrieved from http://unfccc.int/files/meetings/bonn_nov_2017/application/pdf/cp23_auv_agri.pdf

United Nations. (1992). Agenda 21: The United Nations Programme of Action from Rio. New York, USA.

Zdruli, P., Paglai, M., Kapur, S., \& Faz Cano, A. (2010). What we know about the saga of land degradation and how to deal with it? In P. Zdruli, M. Pagliai, S. Kapur, \& A. Faz Cano (Eds.), Land Degradation and Desertification: Assessment Mitigation and Remediation (pp. 3-15). Springer Dordrecht Heidelberg London New York. https://doi.org/10.1007/978-90-481-8657-0_1

Zdruli, P. (2014). Land resources of the Mediterranean: status, pressures, trends and impacts on regional future development. Land Degradation \& Development, 25, 373-384. https://doi.org/10.1002/ldr.2150

Ziadat, F., Mazahreh, S., Haddad, M., Benabdelouahab, T., Attaher, S., Karrou, M., Oweis, T., \& Kandakji, T. (2014). Similarity and Suitability Analysis to Assist the Out-Scaling of Sustainable Water and Land Management Practices in West Asia and North Africa. Research Report, 11, Beirut, ICARDA.

Ziadat, F., Berrahmouni, N., Grewer, U., Bunning, S., Bockel, L., \& Oweis, T. (2015). Reversing land degradation in the drylands: scaling out and monitoring proven sustainable land management options. In J. Griffiths (Ed.), Living land (pp. 14-17). United Nations Convention to Combat Desertification.

Ziadat, F., De Pauw, E., Nachtergaele, F., \& Fetsi, T. (2021). A Land Resources Planning Toolbox to Promote Sustainable Land Management. Sustainable Agriculture Research, 10(1), 73. https://doi.org/10.5539/sar.v10n1p73

\section{Copyrights}

Copyright for this article is retained by the author(s), with first publication rights granted to the journal.

This is an open-access article distributed under the terms and conditions of the Creative Commons Attribution license (http://creativecommons.org/licenses/by/3.0/). 